Revista de la red interuniversitaria de estudios sobre las literaturas rioplatenses contemporáneas en Francia

$22 \mid 2021$

¿Cómo se cuenta una vida? El retorno de lo biográfico en la literatura rioplatense contemporánea

\title{
¿Cómo se cuenta una vida? El retorno de lo biográfico en la literatura rioplatense contemporánea
}

Comment raconte-t-on une vie? Le retour du biographique dans la littérature rioplatense contemporaine

How to tell a life? The return of the biographical writing in contemporary rioplatense literature

Judith Podlubne y Julieta Yelin

\section{OpenEdition}

Journals

Edición electrónica

URL: https://journals.openedition.org/lirico/10721

DOI: $10.4000 /$ lirico.10721

ISSN: 2262-8339

Editor

Réseau interuniversitaire d'étude des littératures contemporaines du Río de la Plata

Referencia electrónica

Judith Podlubne y Julieta Yelin, «¿Cómo se cuenta una vida? El retorno de lo biográfico en la literatura rioplatense contemporánea», Cuadernos LIRICO [En línea], 22 | 2021, Publicado el 11 marzo 2021, consultado el 21 septiembre 2021. URL: http://journals.openedition.org/lirico/10721 ; DOI: https:// doi.org/10.4000/lirico.10721

Este documento fue generado automáticamente el 21 septiembre 2021

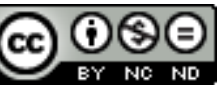

Cuadernos LIRICO está distribuido bajo una Licencia Creative Commons Atribución-NoComercialSinDerivar 4.0 Internacional. 


\title{
¿Cómo se cuenta una vida? El retorno de lo biográfico en la literatura rioplatense contemporánea
}

\author{
Comment raconte-t-on une vie? Le retour du biographique dans la littérature \\ rioplatense contemporaine \\ How to tell a life? The return of the biographical writing in contemporary \\ rioplatense literature
}

Judith Podlubne y Julieta Yelin

A mediados de la década del 70, unos años después de proclamar "la muerte del autor" en favor de las nociones de "texto" y "escritura", Roland Barthes comenzó a interesarse por lo que designó de modo amplio como la "nebulosa biográfica" (2005: 276). Con el propósito explícito de relativizar las cuestiones conceptuales vinculadas a deslindes genéricos, la categoría reunía la serie de tipos textuales dispuestos a asumir las diversas modulaciones de lo biográfico (diarios, autobiografías, biografías, memorias, correspondencias, entrevistas personalizadas), sin especificar distinciones entre el relato de vidas propias ("escrituras del yo") o ajenas ("escrituras biográficas"). Su libro Roland Barthes por Roland Barthes, de 1975, pero sobre todo las clases que dictó en 1978-1979 y 1979-1980, y que se publicaron póstumamente en el volumen La preparación de la novela (2005), expusieron y desarrollaron una curiosidad renovada por las relaciones entre vida y escritura, vida y obra, y dieron lugar a lo que designó como "escrituras de vida" o "vidas escritas". Por el camino de Proust, en quien reconoció "la entrada masiva, audaz, del autor, del sujeto que escribe, en la literatura" (2005: 278), el concepto de "escritura" recuperaba en estas fórmulas un sentido calibrado que atendía al nexo indisoluble entre biografemática y tanatografía. Vida, muerte y escritura se reclamaban entre sí: la división, la fragmentación, la ruptura, incluso la pulverización del sujeto, definirían el nuevo principio desde el que volver a pensar sus relaciones; ya 
no bajo el modelo de la adecuación entre la vida y la escritura ("simple biografía", apuntaba), sino de las escrituras y los fragmentos, de los planos de vida.

2 En el prefacio a Sade, Loyola, Fourier (1971), anticipando un "retorno amistoso" del autor a los estudios literarios, Barthes acuñó el neologismo "biografema" para aludir a los motivos singulares -"detalles", "gustos", "inflexiones"- que condensan circunstancialmente los sentidos de una vida. Insistió sobre la noción y la perfiló en las sesiones dedicadas al "Atelier sur le biographématique", en el seminario sobre Le lexique de l'auteur que dictó entre 1973 y 1974. El "biografema" se redefine entonces como un "trait de vie significant" (2009: 351); su significancia reside en un desborde de significación -en la ultra- o infrasignificación- que reenvía al cuerpo del lector y no en un sentido previamente constituido y ejemplar. El "trait" se asocia de modo explícito a la idea de "instant prégnant" que Barthes retoma de Lessing en Laokoon y caracteriza en "Diderot, Brecht, Eisenstein", ese mismo año de 1973. La biographématique contaría en adelante con la libertad metodológica de abordar "la double question de l'écriture de vie et de la vie comme écriture", la vie comme oeuvre (2009: 81).

3 La idea del "retorno al autor" o "el retorno al sujeto" en que se sustentaba la vuelta a la "nebulosa biográfica" no comprometía el abandono o la rectificación de posiciones anteriores sino, tal como argumentaron en el ámbito argentino los trabajos de Julio Premat (2009) y Marcelo Topuzian (2014), la ampliación y consolidación de sus propósitos y alcances. Lo que retorna en los años setenta no es la imagen del escritor que había sido muerto y enterrado en los sesenta, con sus conflictos psicológicos y sus compromisos políticos, con su carga espiritual de herencia y de historia, sino la intensidad de un cuerpo que escribe, una afectividad que desborda la biografía como género, que invade la obra, que desestabiliza y problematiza lo que ha sido pensado acerca de esa relación causal -"No es la vida la que se parece a la obra; la escritura conduce" (Barthes 2005: 279)- a través de la experiencia de la íntima animalidad.

Contemporáneos de las teorizaciones de Barthes, también durante la década del 70, empezaron a desarrollarse, por un lado, los primeros aportes teóricos específicos sobre el género autobiográfico. Los estudios de Jean Starobinski [1970] (2008), Philippe Lejeune [1975] (1996) y Paul de Man [1979] (1991) resultaron insoslayables para el progreso de la indagación general en torno a las relaciones entre vida y escritura, lo mismo que, por otro ${ }_{2}$ las reflexiones sobre la categoría de "autoficción" que, en respuesta inmediata a los planteos de Lejeune, impulsó el novelista Serge Doubrovsky ([1977]). Estos planteos reinstalaron la indiscernibilidad de las relaciones entre ficción y referencia como problema teórico fundamental y dieron inicio a los estudios actuales sobre el género (Colonna 2004, Alberca 2007, Gasparini 2008). Finalmente, cabe mencionar las postulaciones pioneras de Michel Foucault [1976] (2002) en torno de las nociones de biopolítica y biopoder, sobre las que se apoya el actual interés por los conceptos de "vida" y de "viviente" desde una perspectiva ética y política, y que son significativamente contemporáneas de sus reflexiones acerca de los "procesos de subjetivación", es decir, de aquellas modalidades de la relación consigo mismo mediante las cuales el individuo se constituye y se reconoce como sujeto (Foucault 2001). Las investigaciones posteriores de G. Deleuze (1996a), G. Agamben (2003 y 2005) y R. Esposito (2006 y 2009), entre otros, continuaron y expandieron estos conceptos, atendiendo en especial a los vínculos entre subjetivación e impersonalidad, vida subjetiva (bíos) y vida impersonal (zoé), vida y lenguaje. El pensamiento de la vida en los términos de una vida, tal y como fue esbozado por Deleuze en su insoslayable ensayo 
"La inmanencia: una vida..." (1996b), advierte sobre la imposibilidad de trazar jerarquías y fronteras precisas entre estos dominios y deja entrever conflictos de indecidibilidad arraigados en la estructuración misma del lenguaje. El problema de la relación entre lenguaje y vida resulta así, desde esta perspectiva, esencial a la hora de estudiar los modos en que se resuelven en la escritura las tensiones entre lo general y lo singular, entre lo comunicable y lo resistente, entre el código compartido y la irreductible materialidad de la experiencia.

5 El texto de Judith Revel cuya traducción incluimos en este número ("La naissance littéraire de la biopolitique"), interviene de modo decisivo en este horizonte de pensamiento al abordar en el corpus foucaultiano la zona de encuentro de dos líneas de investigación con frecuencia disociadas por la crítica: por un lado, sus reflexiones de los años sesenta en torno del discurso, enriquecidas por las lecturas de textos literarios y de trayectorias de escritores que consideraba marginales -en el sentido de excéntricos, transgresores, exploradores de lo que por entonces concebía como un "afuera" del lenguaje-; por otro, su análisis de las relaciones de poder, que a partir de finales de los años setenta se orientarán fundamentalmente a la caracterización de las regulaciones de la vida a través de la conceptualización de la noción de biopolítica. Revel expone y analiza cómo ambos desarrollos encuentran un punto de máxima intensidad mediante el retorno, en los últimos trabajos de Foucault, al problema de la subjetividad: tanto el estudio de la productividad de los discursos como la elaboración de una genealogía del poder necesitan, para ganar espesor crítico, de una historia de los modos de subjetivación, es decir, de aquellos procesos creadores por medio de los cuales "una subjetividad se afirma no sólo negativamente -contra el orden, contra las relaciones de poder cuyo reino fractura- sino también positivamente en el mundo: en resumen, un movimiento constituyente" (10). De esos movimientos, que articulan variables históricas con fuerzas vitales que ponen en escena el cuerpo, la voz, los afectos, la sexualidad, emergen formas de resistencia entre las que, por supuesto, se cuenta la literatura. La escritura de sí y de los otros, la puesta en acto del deseo de contar una vida en su singular rareza, ilumina la dimensión ética, estética y política de aquellos acontecimientos de la existencia que Foucault ha caracterizado como "procesos de subjetivación".

6 La traducción de "L'épuisement du biographique?", el estudio de Vincent Broqua y Guillaume Marche, vuelve a pensar lo biográfico en el escenario abierto por este retorno al autor y a los modos de subjetivación en el que convergen, desde ópticas diferenciadas, las preocupaciones de Barthes y Foucault. El agotamiento de lo biográfico proclamado por el conjunto de las ciencias humanas desde los años cincuenta, en pleno auge estructuralista, no habría redundado en su fin sino en su renovación. Las impugnaciones realizadas al biografismo desde la teoría literaria, con Barthes; desde la filosofía, con Foucault y Deleuze; y desde la sociología, con Pierre Bourdieu, objetaban, empleando enfoques distintos, no siempre convergentes, las determinaciones referencialistas y totalizadoras del género, como consecuencia del escrutinio al que estaban siendo sometidas las nociones de "subjetividad", "escritura" y "vida", entre otras. Atentos a estas impugnaciones, Broqua y Marche proponen "considerar lo biográfico como una condición del regreso de la biografía mediante la superación de la misma" (3). Lo biográfico resultaría entonces un modo, ya no un género, que desbordaría las convenciones de la retórica biográfica e invitaría a revisar una vez más los problemas constitutivos del anudamiento vida-escritura: las relaciones entre verdad y ficción, entre documento y relato, entre vida y obra, entre sujeto e historia. 
Así definido, lo biográfico extendería sus intereses y abarcaría "tanto la escritura de la vida, la expresión del yo, como la manera en que la vida llega a la escritura y la ficción o, para decirlo de otra forma, la manera en la que la vida se cuela en la ficción a través de la escritura." (4)

En el marco de los avances teóricos que reseñamos de manera sumaria, la crítica literaria y cultural latinoamericana manifestó en los últimos tiempos una curiosidad sostenida hacia las "escrituras de vida", al tiempo que incorporó una preocupación por los rasgos que adquieren en ellas las representaciones de lo viviente como potencia virtual que presiona, desplaza y distorsiona las figuraciones convencionales de lo humano. Inscribiéndose en ese horizonte de lectura, el monográfico se propone explorar los modos que presenta el retorno de lo biográfico en la literatura rioplatense contemporánea. Las colaboraciones reunidas examinan las variantes temáticas y formales que asume el relato de una vida, al tiempo que dialogan, cada cual a su manera, con una vertiente del pensamiento filosófico que puso a la vida en el centro de sus preocupaciones, reconfigurando, en ese mismo gesto, las articulaciones entre cuerpo y escritura, voz y letra, zoé, bíos y grafé.

El monográfico se organiza en secciones de límites permeables, que diseñan un itinerario tentativo de lectura. Dado el interés común en los asuntos, la riqueza conceptual de las exposiciones y el diálogo que se despliega entre ellas, hay otros recorridos posibles: implícitos, transversales, imprevistos, más atentos a los estilos de los colaboradores que a los aspectos temáticos. Las secciones propuestas reúnen textos de diferente índole -argumentativa, ensayística, narrativa- que, al tiempo que desarrollan las cuestiones tratadas experimentan y muestran en acto las posibilidades del vínculo entre escritura y vida.

"Borges, el maestro biógrafo" toma su nombre de una ocurrencia de César Aira y nuclea escritos de Matías Serra Bradford, Nora Avaro, Silvio Mattoni y Julio Premat. Todos ellos encuentran una referencia fundamental en las vidas imaginarias y las biografías sintéticas de Borges. Una digresión necesaria antes de avanzar en la descripción del apartado: ¿Asombra todavía que un dossier dedicado a la literatura rioplatense contemporánea empiece convocando a Borges, nuestro clásico del siglo XX? La sola idea de clásico que él postuló alcanzaría para atenuar ese asombro: nada más contemporáneo (e "inactual", para mentar el rigor conceptual de Agamben) que un libro desajustado a su tiempo y, por lo mismo, "capaz de interpretaciones sin término". No obstante, el monográfico compone a su modo, oblicuo y disperso, una explicación ad hoc para esta paradoja aparente. Esta explicación empieza a tramarse en el ensayo de Serra Bradford, que lee Borges y B, de Carlos Mastronardi, y Borges, de Adolfo Bioy Casares, tres libros póstumos, con la convicción de que "las sorpresas en la literatura argentina las sigue deparando el pasado", y se extiende hasta el fragmento "El pasado se mueve", del texto de Alberto Giordano, que reflexiona sobre el valor inconcluso de lo vivido. Entre uno y otro, hay varios momentos de otras colaboraciones que argumentan en favor de esta encrucijada temporal. Por ejemplo, el "anacronismo programático" que Premat detecta y prescribe en las dos novelas actuales de las que se ocupa, El espectáculo del tiempo, de Juan José Becerra y El absoluto, de Daniel Guebel, encierra una vuelta nueva a este problema.

10 Concentrado en caracterizar la maestría propia del Borges biógrafo, su "arte de la invención circunstancial”, el ensayo de Avaro, núcleo gravitante de este apartado, reflexiona sobre el encanto y el rédito que el detalle, el incidente, el azar, le procuran al 
relato sus vidas breves. Avaro sopesa esta maestría en la pista de los precursores a posteriori que él mismo figuró: John Aubrey y Marcel Schwob, pero también Virginia Woolf y Lytton Strachey, y sitúa la peculiaridad borgeana en la impostura máxima que desplegó al abreviar su propia vida. El ensayo de Serra Bradford lee las vidas de Borges en el doble sentido del genitivo, las que se escribieron sobre él y las que él escribió de sí mismo. Encuentra en ellas la oportunidad de especular sobre el obrar biográfico de Mastronardi, Bioy Casares, los cruces que se suscitan en las escrituras de ambos, la actividad biográfica en general, el método de Borges. Las afinidades con Avaro son evidentes. Una coincidencia a favor de los intereses de este dossier es el léxico barthesiano al que ambos recurren. "Maestro del punctum y del biografema", anota Serra Bradford, Borges siempre buscó retratar en pocas pinceladas...”. Mattoni identifica la maestría borgeana con uno de los modos propios de la biografía, aquel en el que el cuento de la vida se cristaliza en un momento crucial, y lo contrasta, a partir de un pasaje de Aira, con otro en el que la biografía se confunde con la novela. El contraste le permite volver a pensar la tensión irresoluble entre vida y escritura, a partir de la forma finita, fragmentaria, de lo escrito. La discontinuidad fundamental del relato es su asunto; le interesa sobre todo captar el movimiento de aquello que ningún fragmento puede unificar, "la vida no discursiva, que entra en los libros por los intersticios, en las transiciones, en el fracaso del afán de continuidad propio de la novela y de su hermana la biografía" (3). Las relaciones entre novela y biografía definen la coordenada general que atraviesa el artículo de Premat. Las dos novelas que interroga y analiza responden a la pregunta sobre cómo se cuenta una vida apelando a modelos identificables de la historia literaria: las de las escrituras del yo, en el caso de Becerra, las de las vidas imaginarias, en el de Guebel. La expansión de lo biográfico, arriesga Premat, respondería al estado actual de la novela: la vida sería la última historia narrable en un momento de debilitamiento de lo novelesco.

11 En la segunda sección, "El ejercicio biográfico", los artículos de Judith Podlubne, Patricio Fontana, Julia Musitano y Nieves Battistoni leen a cuatro de los principales exponentes de del "pequeño auge biográfico de la literatura argentina contemporánea", al decir de Battistoni: Mariana Enriquez sobre Silvina Ocampo, Leila Guerriero sobre Bruno Gelber, Osvaldo Baigorria sobre Néstor Sánchez y Ricardo Strafacce sobre Osvaldo Lamborghini. Los oficios del biógrafo, sus apuestas y resultados, los aciertos, los riesgos, los efectos inadvertidos, configuran las preocupaciones comunes del apartado. Con el examen crítico de las obras elegidas, $L a$ hermana menor. Un retrato de Silvina Ocampo, Opus Gelber, Sobre Sánchez, Osvaldo Lamborghini, una biografía, los colaboradores ofrecen un acercamiento reflexivo y actualizado a distintos aspectos medulares del ejercicio biográfico: la relevancia del lazo entre vida y obra cuando se cuenta una vida de escritor, el lugar de los testimonios y las versiones en la composición de la biografía, lo que aportan y lo que ocluyen, los modos del vínculo entre biógrafo y biografiado, las vehemencias del amor y la amistad frente a los anhelos historiográficos de objetividad, la conversación como forma de la escritura de vida y no solo como herramienta de la búsqueda biográfica, los problemas del acceso al archivo, su exuberancia y el drama de la totalidad, la biografía monumental, la summa biográfica. El intercambio que los artículos manifiestan en torno a estos aspectos, las referencias bibliográficas comunes, las citas de un colaborador a otro, le otorgan a esta sección una unidad vigorosa, no exenta de matices y diferencias.

La sección "Planos de vida" reúne artículos de Julieta Yelin, Ana Inés Larre Borges, Carina Blixen, Daniela Alcívar Bellolio y Anahí Mallol. En ellos, las autoras exploran 
diversos modos de creación y reflexión en torno del anudamiento escritura-vida en una serie de textos que se inscriben, con variantes genéricas y temáticas, en la "nebulosa biográfica" barthesiana. Las lecturas buscan los términos más adecuados para nombrar y estudiar los movimientos producidos por las derivas de esa relación tan estrecha como inestable y disimétrica: tensión, crisis, aporía, transformación, fragmentación, experimentación. Con ellos, procuran ceñir los efectos del trabajo formal del lenguaje sobre el flujo inasible de la vida, de una vida que resiste. En las memorias urgentes de una escritora moribunda (Alcívar Bellolio), en los textos autobiográficos de dos poetas objetivistas de los años noventa (Mallol), en las cartas de un joven pianista que quiere hacerse escritor (Yelin), en el diario literario y plástico de un escritor maduro (Blixen) y en los poemas políticos de una poeta intimista (Larre Borges), se ensayan formas narrativas y poéticas que se atreven a vérselas con la vida: a ordenarla, diseccionarla, interpretarla, inventarla..., en fin, que procuran contarla para hacerla llegar a un lector que pueda, a su vez, recrear una vida nueva. Todos esos planos que en los textos de Andrea Rabih, Silvio Mattoni, Alejandro Rubio, Felisberto Hernández, Carlos Liscano e Idea Vilariño dibujan trayectorias vitales y literarias, exponen al mismo tiempo, gracias a la curiosidad y los hallazgos de las intervenciones críticas, la fragilidad de los hilos que tejen todo relato de vida.

Los dos textos que incluimos bajo la rúbrica "El arte del olvido" participan también de la conversación en torno de las posibilidades críticas y creativas de la relación vidarelato, pero lo hacen con recursos bien diferentes: Jorge Monteleone y Alberto Giordano enlazan de modo sensible la reflexión metaliteraria con el ejercicio autobiográfico, produciendo un pensamiento novedoso acerca de las formas que puede adquirir la narración de lo vivido, esto es, de los efectos producidos por el trabajo del olvido y de su resto, la memoria. "La escritura de El centro de la tierra (lectura e infancia)" realiza un viaje al corazón de la experiencia de la lectura; el narrador sostiene que en los libros de la infancia todavía se pueden sentir el sabor y el calor de un tiempo y un mundo perdidos que, sin embargo, acompañan al lector adulto como un misterio siempre encendido. "No es un recuerdo, sino una sensación" anota Monteleone cuando relata el reencuentro con viejos ejemplares de Julio Verne, de Mark Twain, con las hojas raídas de antiguas revistas. "Lo que regresaba no era la infancia en la lectura, sino la sensación de lo que quedaba de ella en los objetos que yo tenía entre las manos" (2). En "Cada vez por única vez. Un diario de lecturas", Giordano, por su parte, anota impresiones y reflexiones sobre una serie de escritos autobiográficos que aguijonearon su interés al iluminar alguna zona de ese territorio soberano e incognoscible de la vida narrada. En algunos pasajes de esos textos, reconoce la puesta en acto de las paradojas de la rememoración, ejercicio obstinado en fijar lo que irremediablemente se escapa. Cuando en esas dramatizaciones del pasado o de la propia identidad, en lugar de intentar darse a conocer, el narrador procura conocerse, "salta más allá de su afirmación narcicista y se somete activamente a la prueba de lo incierto" (2). Se produce así, ante los ojos del lector, la alquimia literaria. El crítico-diarista nos regala su descubrimiento al tiempo que carga de nuevos sentidos su propia experiencia de escritura. 


\section{BIBLIOGRAFÍA}

Agamben, G., El lenguaje y la muerte, Valencia, Pre-Textos, 2003. Traducción de Tomás Segovia. ---, Lo abierto. El hombre y el animal, Valencia, Pre-Textos, 2005. Traducción de Antonio Gimeno Cuspinera.

Alberca, M., El pacto ambiguo. De la novela autobiográfica a la autoficción, Madrid, Biblioteca Nueva, 2007.

Barthes, Roland, “Diderot, Brecht, Eisenstein”, en Lo obvio y lo obtuso. Imágenes, gestos, voces, Barcelona, Paidós, 1986. TRaducción de Critstina Fernández Medrano.

---, La preparación de la novela. Notas de cursos en el Collège de France, 1978-1980. Buenos Aires, Siglo XXI, 2005. Traducción de Patricia Wilson.

---, Le lexique de l'auteur : séminaire à l'Ecole pratique des hautes études 1973-1974, suivi des fragments inédits du Roland Barthes par Roland Barthes, París, Seuil, 2009.

Colonna,V., Autofiction et autres mytho manies littéraires, París, Tristram, 2004.

De Man, Paul, "La autobiografía como desfiguración", Anthropos: Boletín de información y documentación, nº Extra 29, 1991, Barcelona, Anthropos, p. 113-118.

Deleuze, G., Crítica y clínica, Barcelona, Anagrama, 1996a. Traducción de Thomas Kauf.

---, “La inmanencia: una vida...”, Sociología, no 19, 1996b, Medellín, UNAULA Facultad de Sociología, p.233-236. Traducción de Consuelo Pabón.

Doubrovsky, S., Fils, París, Galilée, 1977.

Esposito, R., Bíos. Biopolítica y filosofía, Buenos Aires, Amorrortu, 2006. Traducción de Carlo R. Molinari.

---, Tercera persona. Política de la vida y filosofía de lo impersonal, Buenos Aires, Amorrortu, 2009. Traducción de Carlo R. Molinari.

Foucault, M., Hermenéutica del sujeto: curso en el collège de France (1981-1982), Buenos Aires, Fondo de Cultura Económica, 2001. Traducción de Horacio Pons.

---, Historia de la sexualidad 1: La voluntad de saber, Buenos Aires, Siglo XXI, 2002. Traducción de Ulises Guiñazú.

Gasparini, P., Autofiction. Une aventure du langage, París, Seuil, 2008.

Lejeune, P. , Le pacte autobiographique, París, Seuil, 1996.

Premat, J., Héroes sin atributos. Figuras de autor en la literatura argentina, Buenos Aires, FCE, 2009.

Starobinski, J., "El estilo de la autobiografía”, en La relación crítica, Buenos Aires, Nueva Visión, 2008. Traducción de Ricardo Figueira.

Topuzian, M., Muerte y resurrección del autor (1963-2005), Santa Fe, Universidad Nacional del Litoral.

\section{RESÚMENES}

Los textos aquí reunidos abordan las variantes temáticas y formales que asume el relato de una vida en la literatura rioplatense de las últimas décadas. Rastrean, además, los diálogos que esos 
textos establecen con una vertiente del pensamiento contemporáneo que puso a la vida en el centro de sus preocupaciones, reconfigurando, en ese mismo gesto, las articulaciones entre cuerpo y escritura, voz y letra, zoé y bíos. La pregunta “¿cómo se cuenta una vida?" funcionó como una invitación a explorar el estado actual de las "escrituras de vida" en el Río de la Plata; las respuestas que ofrecen los artículos brindan un panorama reflexivo y actualizado sobre esas escrituras, así como también un mapa de las estrategias con que la crítica del presente se enfrenta a la siempre rica y tensa relación entre literatura y vida.

Les textes rassemblés ici abordent les variantes thématiques et formelles assumées par le récit d'une vie dans la littérature du Rio de la Plata au cours des dernières décennies. Ils retracent également les dialogues que ces textes établissent avec un courant de la pensée contemporaine qui a placé la vie au centre de ses préoccupations, reconfigurant, dans ce même geste, les articulations entre corps et écriture, voix et lettre, zoé et bíos. La question "comment se raconte une vie" a servi d'invitation à explorer l'état actuel des " écritures de vie" dans le Río de la Plata ; les réponses offertes par les articles fournissent un panorama réfléchi et actualisé de ces écrits, ainsi qu'une carte des stratégies avec lesquelles les critiques actuels confrontent la relation toujours riche et tendue entre la littérature et la vie.

The texts collected here address the thematic and formal variants that the telling of a life has taken on in the literature of the Rio de la Plata region in recent decades. They also trace the dialogues that these texts establish with a strand of contemporary thought that has placed life at the centre of its concerns, reconfiguring, in that very gesture, the articulations between body and writing, voice and letter, zoé and bíos. The question "how is a life told?" functioned as an invitation to explore the current state of "life writing" in the Río de la Plata; the answers offered by the articles provide a reflective and updated panorama of such writing, as well as a map of the strategies with which present-day critics confront the always rich and tense relationship between literature and life.

\section{ÍNDICE}

Palabras claves: Una vida, escritura, lo biográfico, literatura rioplatense contemporánea Keywords: A life, writing, the biographical, contemporary Rio de la Plata literature Mots-clés: Une vie, écriture, le biographique, la littérature rioplatense contemporaine

\section{AUTORES}

\section{JUDITH PODLUBNE}

(IECH - UNR, CONICET)

judithpodlubne@gmail.com

JULIETA YELIN

(IECH - UNR, CONICET)

julietayelin@conicet.gov.ar 